\title{
Systematic review and meta-analysis on the effect of continuous subjective tinnitus on attention and habituation
}

\author{
Harini Vasudevan ${ }^{1}$, Kanaka Ganapathy ${ }^{1}$, Hari Prakash Palaniswamy ${ }^{\text {Corresp., } 1}$, Grant Searchfield ${ }^{2}$, Bellur Rajashekhar \\ ${ }^{1}$ Department of speech and hearing, Manipal College of Health Professions (MCHP), Manipal Academy of Higher Education (MAHE), Manipal, karnataka, \\ India \\ ${ }^{2}$ Faculty of Medical and Health Sciences, University of Auckland, Auckland, New Zealand \\ Corresponding Author: Hari Prakash Palaniswamy \\ Email address: hari.prakash@manipal.edu
}

Background: Attention and habituation are two domains known to play key roles in the perception and maintenance of tinnitus. The heterogeneous nature of tinnitus and the methodologies adopted by various studies make it difficult to generalize findings. The current review aims at assessing and synthesizing evidence on the possible roles of attention and habituation in continuous subjective tinnitus.

Methodology: The literature search included five databases (PubMed, Scopus, Web of Sciences, CINAHL and ProQuest) that resulted in 1293 articles, published by July 2019. Studies on attention and/or habituation in individuals with tinnitus using either behavioural or electrophysiological tests were included in the review after a quality assessment.

Results: Seventeen studies on attention in tinnitus were included in the narrative synthesis. Two metaanalyses were performed to assess the role of attention in tinnitus using a behavioural methodology ( $z$ $=4.06 ; p<0.0001)$ and $\mathrm{P} 300$ amplitude $(z=2.70 ; p=0.007)$ with 531 participants. With respect to habituation, the review indicates the lack of quality articles for habituation inclusion in the narrative synthesis.

Conclusions: The review highlights that selective domains of attention were consistently impaired in individuals with tinnitus. Habituation, on the other hand, needs further exploration. 
1 Manuscript Title

2 Systematic review and meta-analysis on the effect of continuous subjective tinnitus on

3 attention and habituation

4 Ms. Harini Vasudevan (HV) ${ }^{1}$ Dr. Kanaka Ganapathy $(\mathrm{KG})^{2}$, Dr. Hari Prakash Palaniswamy

$5 \quad(\mathrm{HP})^{3 *}$, Dr. Grant Searchfield (GS) ${ }^{4}$ and Dr. B. Rajashekhar (BR $)^{5}$

6

$7{ }^{1}$ Ph.D. Scholar, Department of Speech and Hearing, Manipal College of Health Professions

8 (MCHP), Manipal Academy of Higher Education (MAHE), Manipal. India.

$9{ }^{2}$ Associate Professor, Department of Speech and Hearing, Manipal College of Health

10 Professions (MCHP), Manipal Academy of Higher Education (MAHE), Manipal. India.

$113 *$ Associate Professor, Department of Speech and Hearing, Manipal College of Health

12 Professions (MCHP), Manipal Academy of Higher Education (MAHE), Manipal. India.

$13{ }^{4}$ Associate Professor, Director Hearing and Tinnitus Clinic, Faculty of Medical and Health

14 Sciences, University of Auckland, New Zealand.

$15{ }^{5}$ Professor, Department of Speech and Hearing, Manipal College of Health Professions

16 (MCHP), Manipal Academy of Higher Education (MAHE), Manipal. India.

17

18

19

20

21

22

23

24

25

26

27

28

29

30

31

32

33

34

35

36

37

38

39

40

41

\section{Corresponding Author:}

Dr. Hari Prakash Palaniswamy (HP) ${ }^{3 *}$

Associate Professor, Department of Speech and Hearing, Manipal College of Health Professions (MCHP), Manipal Academy of Higher Education (MAHE), Manipal. India.

Email address: hari.prakash@manipal.edu

\section{Abstract}

Background: Attention and habituation are two domains known to play key roles in the perception and maintenance of tinnitus. The heterogeneous nature of tinnitus and the methodologies adopted by various studies make it difficult to generalize findings. The current review aims at assessing and synthesizing evidence on the possible roles of attention and habituation in continuous subjective tinnitus.

Methodology: The literature search included five databases (PubMed, Scopus, Web of Sciences, CINAHL and ProQuest) that resulted in 1293 articles, published by July 2019. Studies on attention and/or habituation in individuals with tinnitus using either behavioural or electrophysiological tests were included in the review after a quality assessment.

Results: Seventeen studies on attention in tinnitus were included in the narrative synthesis. Two meta-analyses were performed to assess the role of attention in tinnitus using a behavioural methodology $(\mathrm{z}=4.06 ; \mathrm{p}<0.0001)$ and $\mathrm{P} 300$ amplitude $(\mathrm{z}=2.70 ; \mathrm{p}=0.007)$ with 531 participants. With respect to habituation, the review indicates the lack of quality articles for habituation inclusion in the narrative synthesis.

Conclusions: The review highlights that selective domains of attention were consistently impaired in individuals with tinnitus. Habituation, on the other hand, needs further exploration. 
42 Keywords: Systematic review, Attention, Habituation, and Tinnitus.

43

44

45

46

47

48

49

50

51

52

53

54

55

56

57

58

59

60

61

62

63

64

65

66

67

68

69

70

71

72

73

74

75

76

77

78

79

80

81

\section{Introduction}

Tinnitus is the conscious awareness of a tonal or composite noise for which there is no identifiable corresponding external acoustic source (De Ridder et al., 2021). The pathophysiology of tinnitus is complex involving various cortical and subcortical systems with primary damage to the auditory periphery (Galazyuk, Wenstrup, \& Hamid, 2012). It manifests either continuously, or in an intermittent form, and is experienced by about $10-15 \%$ of the world's population based on various epidemiological studies (Baigi, Oden, Almlid-Larsen, Barrenäs, \& Holgers, 2011; Gopinath, McMahon, Rochtchina, Karpa, \& Mitchell, 2010; Hasson, Theorell, Wallén, Leineweber, \& Canlon, 2011; Hasson, Theorell, Westerlund, \& Canlon, 2010; Michikawa et al., 2010; Park et al., 2014; Shargorodsky, Curhan, \& Farwell, 2010). However, only a portion of individuals having tinnitus find it disturbing with a recent suggestion that this more disabling tinnitus be defined as Tinnitus Disorder (De Ridder et al., 2021). A contributing factor to Tinnitus Disorder may be the attention focused on tinnitus and an individual's ability to become habituated to the tinnitus sound. Attention, a major domain under cognition, is the process of allocating cognitive resources to focus on information processing. Attention includes sub-domains like alerting, orienting, sustained attention, selective attention, divided attention and executive attention. Active or passive attention towards the tinnitus could drive the cognitive resources away from the primary task that is being performed. In addition, it also makes habituation to tinnitus difficult resulting in decompensating or chronic tinnitus.

Over the years, different types of attention have been studied using behavioural tests like the Stroop task, vigilance task, divided and sustained attention tasks, flanker's paradigm or using electrophysiological measures like P300 and Mismatch Negativity (MMN) for studying active and passive attention, respectively. MMN reflects the pre-attentive process to discriminate the stimulus based on their perceptual characteristics (Näätänen, 2001). Whereas, P300 reflects a higher-level attentional resource and working memory update during the process of perceptual discrimination (Polich, 2012). Although a majority of literature supports that attention is affected in individuals with tinnitus (Andersson, Eriksson, Lundh, \& Lyttkens, 2000; Asadpour, Alavi, Jahed, \& Mahmoudian, 2018; Cuny, Norena, El Massioui, \& Chéry-Croze, 2004; dos Santos Filha \& Matas, 2010; Gabr, Abd El-Hay, \& Badawy, 2011; Heeren et al., 2014; Hong, Park, Ahn, \& Min, 2016; Jackson, Coyne, \& Clough, 2014; Li et al., 2016; Lima et al., 2020; Mahmoudian et al., 2013; Mannarelli et al., 2017; Mohebbi et al., 2019; Stevens, Walker, Boyer, \& Gallagher, 2007; Wang et al., 2018), some studies do not (Davies, McKenna, \& Hallam, 1995; Elmorsy \& Abdeltawwab, 2013; Hallam, McKenna, \& Shurlock, 2004; Houdayer et al., 2015; Najafi \& Rouzbahani, 2020; Shiraishi et al., 1991; Waechter \& Brännström, 2015). The inconsistency in the literature results in ambiguity as to the true role of attention in tinnitus.

Habituation is a form of learning wherein the response to a stimulus that has been repeated or presented for a long time decreases or ceases (Bouton, 2007). Habituation or passive extinction is essential for the brain to perform multiple tasks simultaneously. The brain constantly updates its 
82

83

84

85

86

87

88

89

90

91

92

93

94

95

96

97

98

99

100

101

102

103

104

105

106

107

108

109

110

111

112

113

114

115

116

117

118

119

120

121

schema based on the incoming sensory input. Repeated presentation of stimulus is considered as predictable by the brain and as a result, the perceptual salience allocated to it is less (Durai, O'Keeffe, \& Searchfield, 2018). Habituation is a core premise of several important models of tinnitus including the neurophysiological model, (Jastreboff, 1990), habituation model (Hallam, Rachman, \& Hinchcliffe, 1984) and therapies like tinnitus retraining therapy, (Jastreboff \& Jastreboff, 2000); habituation therapy (Andersson \& McKenna, 1998; Coles \& Hallam, 1987) and guided therapy (Slater, Terry, \& Davis, 1987).

Jastreboff's tinnitus model suggests that persons with tinnitus, but without associating any negative emotions, can become habituated to the tinnitus (Jastreboff, Gray, \& Gold, 1996). The perception of tinnitus gets enhanced only when a person is consciously paying attention to it. Until a negative emotion gets tagged to this sound, the limbic and autonomic nervous system(ANS) co-activation with the tinnitus sound is limited. However, when paired the ANS gets conditioned to the tinnitus signal and negative reactions like fear and annoyance accompany tinnitus, creating a "vicious cycle". The presence of this negative reinforcement from the associated systems makes it difficult for habituation to occur.

Habituation to an external sound may be different from habituation to the internal sounds like tinnitus. Since there are no standardized test to study habituation to tinnitus, measures like P50 can be used to evaluate the sensory gating thereby indirectly assessing habituation. "Sensory gating" is a phenomenon where the brain automatically analyses the incoming stream of information based on its salience to determine the weight that must be given to the stimulus. P50, is an electrophysiological measure that is used widely to evaluate the sensory gating mechanism at the thalamo-cortical level using a paired click paradigm. The redundant or the second click in the paradigm is given less importance, which is observed as reduced P50 amplitude for the redundant stimuli. Individuals having schizophrenia are reported have reduced sensory gating abilities (Shen et al., 2020). With respect to sensory gating in tinnitus population, there are only a handful of studies that have assessed sensory gating in tinnitus experimentally suggesting affected sensory gating in individuals with tinnitus (Campbell, Bean, \& LaBrec, 2018; Campbell, LaBrec, Bean, Nielsen, \& So, 2019) while others suggested it to be normal (Dornhoffer, Danner, Mennemeier, Blake, \& Garcia-Rill, 2006).

Attention and habituation appear to be two important domains in the perception and maintenance of tinnitus. The current review differs from the existing reviews (Cardon et al., 2020; Clarke, Henshaw, Akeroyd, Adams, \& Hoare, 2020) in such a way that, we explore the effect of continuous tinnitus on attention and habituation solely instead of cognition as a whole. Assessing these two specifically in individuals with tinnitus is crucial to understand the roles these domains play, the selection and development of appropriate therapies. In addition, the existing reviews have not addressed the behavioral and electrophysiological indices of attention together nor have, they assessed attention in tinnitus by controlling confounders like hearing loss. Furthermore, existing 
122 reviews have included studies with pulsatile tinnitus making the group heterogenous. The current 123 review aims to overcome the above by exploring the sustained effect of continuous and subjective 124 tinnitus on attention and habituation using both behavioral and electrophysiological measures in 125 adults.

126

\section{Survey methodology}

128

129

The current review protocol was registered and approved by PROSPERO (CRD42019127207).

131

132

\section{Keyword Build}

Using the Cochrane library, Medical term $[\mathrm{MeSH}]$ search engine, all necessary terms for keyword "Tinnitus" along with the "Attention" or "Habituation were identified, and the search string was 133 built using appropriate Boolean operators. (Key words: Tinnitus [MeSH], AND "P300", OR "auditory P3", OR P3, OR "cognitive potential", OR "stroop task", OR "Attentional network task", OR "ANT", OR "Attentional network test", OR "flankers", OR "flankers paradigm ", OR "flankers test", OR "event related potentials", OR "event related potential", OR ERP, OR "ERPs", OR "cortical auditory evoked potentials" OR "cortical auditory evoked potential" OR "CAEPs" OR "CAEP" OR "stroop test", OR attention, OR "selective attention", OR "auditory selective attention" OR "sustained attention", OR "executive attention", OR "alerting attention" OR "focussed attention", OR habituation, OR "thalamo cortical habituation", OR "cortical habituation", OR "sensory gating", OR "auditory gating", OR "mismatch negativity", OR "MMN", OR "P50").

Search Strategy

Thirty-six keywords were used to search five major databases including PubMed, Scopus, Web of Sciences, CINAHL and ProQuest. There were no restrictions pertaining to language. The search was predominantly run through the title and/or abstract of all articles published till the $25^{\text {th }}$ of July 2019. 1293 articles were retained, after removing duplicates $(n=978)$ in Covidence software.

\section{Title and Abstract Screening/ Selection Process}

Two independent reviewers (Reviewer 1, HV and Reviewer 2, KG) screened the articles through title and abstract. Conflicts that arose were resolved by reviewer 3 (HP). On this initial screening, 102 articles that assessed attention and/or habituation in individuals with tinnitus qualified for fulltext screening.

155

\section{Full-Text Screening}

A similar screening was carried out by two reviewers (HV and $\mathrm{KG}$ ) independently with conflict 159 resolution by reviewer 3 , HP.

\section{Inclusion-exclusion Criteria}


161

162

163

164

165

166

167

168

169

170

171

172

173

174

175

176

177

178

179

180

181

182

183

184

185

186

187

188

189

190

191

192

193

194

195

196

197

198

199

200

- Studies that assessed continuous subjective tinnitus on the adult population (18 years and above) that addressed attention and/or habituation using either behavioural or electrophysiological measures were included.

- Study types including observational, cross-sectional studies, case-control or cohort studies were included for full-text screening.

- Articles that addressed only simulated tinnitus, pulsatile tinnitus, qualitative study on an individual's experience with tinnitus, treatment (controlled trials and RCTs), and systematic reviews were eliminated

- Articles in languages other than English were eliminated.

Based on full-text screening, 33 articles were found suitable for the narrative review.

\section{Risk of Bias (ROB) Analysis}

Quality assessment of 33 articles was carried out by two independent reviewers (Reviewer 4, GS and Reviewer 5, BR) and conflicts resolved by reviewer 3 (HP). To screen the risk of bias, appropriate questions from CASP (Critical Appraisal Skilled Programme for case-control studies) were considered. The studies were appraised based on whether they utilized a thorough and appropriate methodology, the meaning and credibility of study findings, and their relevance. Based on the above, the reviewers were asked to rate the risk of bias of the articles on a 5-point scale from very high risk to very low risk. Based on collective inputs from the reviewers, 16 articles were rejected. The ROB analysis and the reasons for rejection are shown in the supplementary file. Finally, 17 studies with low to moderate risk were included in the narrative synthesis. The complete process from searching for articles to those included in the review is represented in the PRISMA chart (Figure 1).

\section{Data Extraction}

Data extraction was carried out in an excel spreadsheet by two independent reviewers (HV and $\mathrm{KG}$ ). The data extracted included the following: age range of participants, gender, number of participants in each group, place of study, matching of controls, tinnitus pitch and loudness, tinnitus laterality, duration, severity, history of previous treatment, residual inhibition information, scales used to assess tinnitus, participants hearing level, degree of hearing loss, screening for psychological characteristics, the behavioral or electrophysiological test performed with an elaborate method, outcome, and justification, stimulus modality, stimulus information like frequency, duration, intensity, inter-stimulus interval, the instrument used, channel information, pre-processing of data, statistical analysis, the main findings of the study with justification, possible treatment options for tinnitus and future directions. The extracted data were placed into different categories namely, general information, tinnitus characteristics, hearing acuity, psychological and psychiatric screening, the test used and outcomes, stimulus, and instrumentation information and the main results, discussion, and future direction.

\section{Data Synthesis}


201 The extracted data was synthesized into a narrative form under various categories including age 202 and gender, place of study, the tinnitus characteristics, hearing acuity, psychological and 203 psychiatric factors, the overall test done with their outcomes, and the instrumentation used. For 204 those articles where quantitative data were obtained a meta- analysis was performed.

205

206

\section{Meta-analysis:}

208

Those articles with necessary quantitative data were synthesized into a meta-analysis using Review Manager (version 5.2). Two meta-analyses were performed to find the effect of tinnitus on attention. Firstly, using the reaction time in milliseconds provided by the behavioral studies and secondly with the P300 amplitude in microvolt from the electrophysiological studies. A randomeffects meta-analysis was done using the standardized mean difference (SMD) for the behavioral studies and Mean Difference (MD) for the P300 studies between the tinnitus and control group with a 95\% confidence interval. Further a subgroup analysis on the basis of hearing was conducted. Two random effects meta-analyses were conducted with those who have matched for hearing and those who have not matched. The results of the meta-analysis were evaluated based on the pooled

217 evidence to calculate the overall effect ( $p$-value).

219 Out of the seventeen studies included, nine used behavioural tests to assess one or more types of attention; the other eight employed an electrophysiological paradigm to assess the same. With

221

222 respect to habituation, no studies passed the risk of bias assessment to be included in the narrative synthesis.

\section{Narrative Synthesis}

\section{Age and Gender}

226

Matching age and gender in hearing research is one of the essential steps in case-control design to

227 create a homogenous group. In the current review, it was found that, out of the seventeen studies, sixteen had controlled either age and/or gender. Most of the studies had matched for age except

229

230

231

232 for Cuny et al. (2004) and Houdayer et al. (2015). Seven studies had included the geriatric population (60 years and older) (Andersson et al., 2000; Araneda, De Volder, Deggouj, \& Renier, 2015; Heeren et al., 2014; Rossiter, Stevens, \& Walker, 2006; Shiraishi et al., 1991; Stevens et al., 2007; Trevis, McLachlan, \& Wilson, 2016). All the studies matched for gender except for five

233 (Houdayer et al., 2015; Jackson et al., 2014; Rossiter et al., 2006; Shiraishi et al., 1991; Stevens et al., 2007).

235

Place of study

236

Eight of the studies were carried out in European countries (United Kingdom, Sweden, Belgium,

237 Rome, Italy, France, and Spain), three in Australia, two each in Israel and Iran, one in Japan and

238

239 one in Korea.

240 Six of the seventeen studies provided tinnitus pitch match results while five matched the loudness 241 of tinnitus. Most of the studies $(n=12)$ had included participants with both unilateral and bilateral 
242 tinnitus. All studies, except Shiraishi et al. (1991) and Cuny et al. (2004), had included tinnitus 243 duration information. The duration of tinnitus ranged from 3 months to 7 years. The commonly 244 used questionnaires were Tinnitus Handicap Inventory, THI (Newman, Jacobson, \& Spitzer, 1996) 245 ( $\mathrm{n}=7)$, Tinnitus Questionnaire, TQ (Hallam, Jakes, \& Hinchcliffe, 1988) ( $\mathrm{n}=6$ ), Tinnitus Sample 246 Case History Questionnaire, TCSHQ (Langguth et al., 2007), Subjective Tinnitus Severity Scale, 247 STSS (Halford \& Anderson, 1991), Tinnitus Reaction Questionnaire, TRQ (Wilson, Henry, 248 Bowen, \& Haralambous, 1991), Tinnitus Psychological Impact Questionnaire, QIPA (Philippot, 249 Nef, Clauw, de Romrée, \& Segal, 2012), and Tinnitus Severity and Symptom profile questionnaire 250 (Barnea, Attias, Gold, \& Shahar, 1990). However, Attias, Urbach, Gold, and Shemesh (1993) and 251 Shiraishi et al. (1991) did not report the use of any questionnaire. The tinnitus characteristics of 252 253

254

255

256

257

258

259

260

261

262

263

264

265

266

267

268

269

270

271

272

273

274

275

276

277

278

279

280

281

282

283

284

\section{Psychological and Psychiatric factors}

Nine of the studies (Andersson et al., 2000; Araneda et al., 2015; Heeren et al., 2014; Jackson et al., 2014; Mannarelli et al., 2017; Rossiter et al., 2006; Stevens et al., 2007; Trevis et al., 2016; Waechter \& Brännström, 2015) had screened for psychological factors such as anxiety and depression, while five did not (Cuny et al., 2004; Hong et al., 2016; Houdayer et al., 2015; Mahmoudian et al., 2013; Mohebbi et al., 2019). Attias et al. (1993) and Attias et al. (1996) based on interviews excluded individuals with psychological complaints. Shiraishi et al. (1991) reported undertaking psychological tests but had not reported the findings. Various questionnaires including Hospital Anxiety and Depression Scale (Snaith, 2003), State-Trait Anxiety Inventory (Spielberger, 1983), Beck's Depression Inventory (Beck, Ward, Mendelson, Mock, \& Erbaugh, 1961), Cognitive Failures Questionnaire (Broadbent, Cooper, FitzGerald, \& Parkes, 1982), Mini-Mental State Examination (Folstein, Folstein, \& McHugh, 1975), Cornell Medical index test (Brodman, Erdmann, Lorge, Wolff, \& Broadbent, 1951), Zung depression questionnaire (Zung, 1965), Becks Anxiety Inventory (Beck \& Steer, 1988), and Subjective Depression Rating Scale (Zung, Richards, \& Short, 1965) had been used to screen participants psychological status.

\section{Behavioural and Electrophysiological tests used and outcomes}

The various tests carried out to assess attention with their major outcome are shown in Table 3 . Out of the seventeen studies, fourteen reported one or other forms of attention being affected in individuals with tinnitus. 


\section{Instrumentation}

288

289

290

291

292

293

294

295

296

297

298

299

300

301

302

303

304

305

306

307

308

309

310

311

312

313

314

315

316

317

318

319

320

321

322

323

324

325

A total of eight studies had used electrophysiological measures. Four used a multichannel system with 29 to 32 channels (Hong et al., 2016; Houdayer et al., 2015; Mahmoudian et al., 2013; Mohebbi et al., 2019) and the remaining, between 3 and 5 channels. Stimuli used to elicit ERPs included Pure Tones, Tone Burst, a light flash and novel sounds. The intensity of the stimulus delivered was 50 decibels (Sound Pressure Level, SPL/ Hearing Level, HL or Sensation Level, SL, elaborated in Table 4) and above. Houdayer et al. (2015) and Attias et al. (1996) have not provided intensity information. Most studies had used a simple oddball ratio of 80:20 except Mahmoudian et al. (2013), Mohebbi et al. (2019) who used 50:50 ratio with multiple deviants. Shiraishi et al. (1991) used an S1-S2 paradigm with 50:50 ratio.

\section{Meta-analysis of Behavioural tests}

The nine behavioural tests included in the papers had tested various forms of attention (selective attention, executive attention, divided attention, alerting and orienting) either directly or indirectly. Eight of the nine studies were included in the meta-analysis based on data availability. The mean, standard deviation (SD), the total number of participants in each group, SMD with $95 \%$ Confidence Interval are depicted in figure 2 . The results of the meta-analysis indicated that individuals with tinnitus have difficulty $(\mathrm{p}<0.001)$ in attentional tasks (Figure 2$)$.

Results from behavioural studies had indicated that individuals with tinnitus had altered inhibitory control and experienced cross-modal interference (Araneda et al., 2015), a specific deficit in executive attention (Heeren et al., 2014), a general disturbance in the automatic attentional process that prevents the deviant detection system from working (Cuny et al., 2004), controlled processing task affected (Rossiter et al., 2006), a deficit in selective \& divided attention (Stevens et al., 2007), poor executive performance (Jackson et al., 2014) and/or reduced control inability to switch attention (Trevis et al., 2016). The study by Waechter and Brännström (2015) was the only one to find no difference in the cognitive interference (using a modified Stroop paradigm) between individuals with tinnitus and control participants.

\section{Subgroup analysis:}

Since hearing is a strong confounder, a subgroup analysis was performed on the behavioural studies used for meta-analysis. Out of the eight, three (Araneda et al., 2015; Trevis et al., 2016; Waechter \& Brännström, 2015) have matched for hearing, while the rest did not. A meta-analysis performed on studies which did not match the hearing of the participants resulted in a significant pooled estimate $(p<0.0001)$. However, when a meta-analysis was solely performed on three studies that matched for the hearing, it did not result in a significant estimate $(\mathrm{p}=0.10)$. The meta-analysis for the studies that have matched and not matched for hearing are shown in figure 3 and 4 respectively. The results of the subgroup analysis conclude that when hearing is matched between the groups, attention is not necessarily affected in individuals with tinnitus. Hence, matching the groups based on hearing is very essential. 
327

328

329

330

331

332

333

334

335

336

337

338

339

340

341

342

343

344

345

346

347

348

349

350

351

352

353

354

355

356

357

358

359

360

361

362

363

364

365

\section{Meta-analysis of Electrophysiological studies}

Out of the eight ERP studies, six measured P300 and two, the MMN. Both the MMN studies (Mahmoudian et al., 2013; Mohebbi et al., 2019) had reported an impaired pre-attentive sensory memory or change detection process in individuals with tinnitus. Due to the limited number of studies, a meta-analysis was not performed on MMN in tinnitus.

Of the six P300, four reported reduced P300 amplitude in individuals with tinnitus (Attias et al., 1996; Attias et al., 1993; Hong et al., 2016; Mannarelli et al., 2017); no difference was found in two of the studies (Houdayer et al., 2015; Shiraishi et al., 1991). The mean and SD of P300 amplitude were unavailable from three studies for meta-analysis (Attias et al., 1993; Hong et al., 2016; Mannarelli et al., 2017). By corresponding with the respective authors, the missing data were obtained for one study and the remaining, missing data (standard deviation) was derived by using the F-values and mean. A random-effects meta-analysis was performed with the mean difference of P300 amplitude between the control and tinnitus group with six studies. The results showed that the P300 amplitude was significantly reduced in individuals with tinnitus (Figure 5). P300 amplitude is sensitive to resource allocation (Polich, 2007) and task difficulty. Justification for a reduction in P300 amplitude in the review articles incuded, depleted cognitive resources to focus on a task, abnormal information processing, improper resource allocation and alteration in the central predictive coding.

With respect to P300 latency, two studies that reported the latency (Houdayer et al., 2015; Shiraishi et al., 1991) had suggested no difference in P300 latency between the tinnitus and the control groups. Only one of six studies had reported prolonged latencies in individuals with tinnitus (Attias et al., 1996). Due to lack of data availability, a meta-analysis on P300 latency was not performed.

\section{Discussion}

Attention and habituation are two intertwined domains proposed to play important roles in the perception and maintenance of tinnitus. The prevailing notion is that increased attention towards tinnitus prevents individuals from habituating to it. This review aimed to find out whether the attention and habituation processes were affected in individuals with tinnitus. To reduce heterogeneity, only studies containing continuous and subjective tinnitus were included. Concerning habituation, none of the studies screened qualified for the narrative synthesis. The main findings from the reviews are discussed in the following sections.

\section{Place of study}

The majority of studies were from Europe; few were from Asia. Studies of groups from several large populations (e.g. China, India, North and South America and Africa) were either not found or meet with the inclusion criteria. Although outcomes of attention assessment are likely to be similar in persons with tinnitus from a different population, it can't be stated with certainty that 
366

367

368

369

370

371

372

373

374

375

376

377

378

379

380

381

382

383

384

385

386

387

388

389

390

391

392

393

394

395

396

397

398

399

400

401

402

403

404

405

406

culture does not play a role. Hence, a globally valid method for the assessment of attention in tinnitus is deemed useful.

\section{Team}

A multidisciplinary team including professionals from audiology, psychology, psychiatry, ENT, neurology, and engineering have collaborated in the majority of the studies. In general, studies based on psychological experiments have considered covariate analysis while occasionally ignoring hearing acuity. Since hearing is a major confounder, there is a need for cognitive psychologists and audiologists to work in close collaboration to design experimental methods for various tinnitus population.

\section{Tinnitus characteristics}

From this review, it is evident that tinnitus of greater than a moderate degree is associated with some amount of attention deficit. However, more studies are warranted to assess whether this deficit is linearly related to tinnitus severity. Apart from this, it was also noted that two scales THI $(n=7)$ and TQ $(n=6)$ were used predominantly. However, studies varied in the use of questionnaires to denote tinnitus characteristics. In addition, tinnitus characteristics such as tinnitus pitch and loudness, have not been reported in most of the studies $(n=11)$. It is felt that standardization of assessment protocols and reporting of results could overcome these problems.

\section{Hearing}

Hearing loss commonly accompanies tinnitus. Eight studies either included individuals with hearing loss and/or did not test their participants' hearing thresholds. Peripheral hearing can solely influence auditory selective attention, by increasing the time to form auditory objects or switch attention rapidly (Shinn-Cunningham \& Best, 2008). Hence, hearing loss is a strong confounder and controlling hearing between the tinnitus and control groups is essential to comment on the influence of tinnitus on an individual's attentional abilities.

\section{Psychological Factors}

Psychological factors such as anxiety and depression are often associated with tinnitus. These factors can influence an individual's attentional abilities. Most of the studies have screened and excluded individuals with anxiety and/or depression (Araneda et al., 2015; Attias et al., 1996; Attias et al., 1993; Hong et al., 2016; Houdayer et al., 2015; Mahmoudian et al., 2013; Mohebbi et al., 2019) as they were considered as major confounders. Few studies have measured and just reported psychological disturbance using anxiety and/or depression scales (Andersson et al., 2000; Mannarelli et al., 2017; Stevens et al., 2007; Trevis et al., 2016), while others considered it as a covariate (Heeren et al., 2014; Rossiter et al., 2006) or matched the psychological status in tinnitus and control group (Jackson et al., 2014; Waechter \& Brännström, 2015). In general, it was observed that studies that employed an electrophysiological methodology just screened the psychological variables (Attias et al., 1996; Attias et al., 1993; Hong et al., 2016; Houdayer et al., 2015; Mahmoudian et al., 2013; Mohebbi et al., 2019). A correlation of such variables with the 
407 ERP results would provide better insight into how anxiety and depression are in individuals with 408 tinnitus.

409

410

411

412

413

414

415

416

417

418

419

420

421

422

423

424

425

426

427

428

429

430

431

432

433

434

435

436

437

438

439

440

441

442

443

444

445

446

\section{Generalizability of results}

The sample size of the individual studies included in the review ranged from 11 to 33 participants per group (mean $=20.52)$. Further, most of the studies did not perform a power analysis. With a low sample size, the generalizability of the individual study results to the population of tinnitus becomes debatable. The current review pooled information from 531 participants to perform a meta-analysis. Therefore, the results of this review could stand as preliminary evidence for an attentional deficit in individuals with tinnitus. However, when the hearing between the groups is matched, attention was not necessarily affected.

\section{Attention in tinnitus}

Attention is a multifaceted process that requires coordination from bottom-up and top-down processes. Salient features of the stimulus guide the bottom-up attentional system through the process of sensory analysis and classification. The internal guidance system formed using prior knowledge, planning and the task goal guides the top-down attention that helps to selectively attend to a stimulus and form appropriate decisions (Katsuki \& Constantinidis, 2014). Any deficit in one or both processes can hamper an individual's attentional ability. In the case of tinnitus, bottom-up and/or top-down processing is believed to be impaired (Asadpour et al., 2018; dos Santos Filha \& Matas, 2010; Gabr et al., 2011; Hong et al., 2016; Richardson, 2018; Vasudevan, Palaniswamy, \& Balakrishnan, 2019; Wang et al., 2018) suggesting a possible dysfunction in the attentional system (Araneda et al., 2018; Cuny et al., 2004; Dornhoffer et al., 2006; Heeren et al., 2014; Li et al., 2016; Mahmoudian et al., 2013; Mannarelli et al., 2017; Milner et al., 2020; Mohamad, Hoare, \& Hall, 2016; Tegg-Quinn, Bennett, Eikelboom, \& Baguley, 2016; Trevis et al., 2016).

In the present review, various behavioural tests including Stroop task, inhibitory test, attentional network task, vigilance test, reading span task, categorization test and divided attention test have been used to study attention. Most of these studies have reported that one or other domains of attention are affected in individuals with tinnitus. The meta-analysis performed in the present review using eight behavioural studies has also indicated that individuals with tinnitus performed poorly at tasks evaluating attention.

With respect to electrophysiological studies, two studies using MMN have reported that passive attention or the pre-attentive change detection process was impaired in individuals with tinnitus. A meta-analysis on P300 amplitude supported a definite alteration in P3 amplitude in individuals having tinnitus indicating an alteration in their selective attention abilities. Due to the nonavailability of data, a similar analysis on the P300 latency was not carried out. 
447 In the current review, more than 90 per cent of the behavioural studies have agreed upon an 448 attentional deficit in individuals with tinnitus. However, only 60 per cent of the 449 electrophysiological studies (using P300 and MMN) have agreed upon the same. This could be 450 attributed to the methodological differences and/or the fact that these behavioural studies did not

451

452

453

454

455

456

457

458

459

460

461

462

463

464

465

466

467

468

469

470

471

472

473

474

475

476

477

478

479

480

481

482

483

484

485

486

487 assess the physiological process associated with attention. Therefore, performing both behavioural and electrophysiological measures on the same individual can give an insight into both the perceptual and physiological attentional changes associated with tinnitus. In addition, studies that differentially assess bottom-up and top-down attention are mandated. As stated, attention is a broad construct \& specific forms of attention need to be probed separately concerning tinnitus. In addition, there is a lack of consistency in reporting the results of these studies, especially those published before 2000. A standardized protocol with appropriate tests to avoid confounders and to report results is needed to integrate the findings from various research.

The review pooled information from seventeen studies. It provides evidence on some form of attentional deficit being present in individuals with tinnitus. Studying various types of attention in each participant in the group is warranted to get a better insight into its differential impact. In addition, it can be deduced that attentional abilities tested using experimental tasks in controlled environments are affected in individuals with tinnitus. Nevertheless, testing attention in real-life situations using everyday tasks would be more appropriate to comment on the attentional abilities in the tinnitus population.

\section{Habituation}

Habituation as a phenomenon has not been studied extensively in individuals with tinnitus. However, improper or lack of habituation to the phantom sound had been proposed to be a major reason for the persistence/maintenance of tinnitus (Hallam et al., 1984; Jastreboff, 1990). A literature search on habituation in tinnitus resulted in a few articles, with inconsistent results. Due to the high risk of bias, many of these studies did not qualify for the narrative synthesis. Most studies on tinnitus in the literature have commented that habituation was affected (Cuny et al., 2004; Heeren et al., 2014; Mohebbi et al., 2019; Rossiter et al., 2006; Stevens et al., 2007; Trevis et al., 2016). However, they have not specifically measured it using behavioural or electrophysiological tests. A possible reason for the absence of evaluation is that tinnitus habituation is hard to test and/or there is a lack of standardized tests for its study (Uus.2016). The creation of a new paradigm or modification of existing paradigms is required to measure habituation in individuals with tinnitus.

\section{Limitations of review}

The most common limitation seen across tinnitus studies is the heterogeneity in participants and methods. It is often difficult to homogenize the groups with respect to tinnitus causes, onset, hearing acuity, psychological factors, tinnitus type and severity. Further, the low sample size of these studies makes it difficult to generalize the results. The review did not include studies that tested Contingent Negative Variation, CNV (Hoke, Mühlnickel, Ross, \& Hoke, 1998; Kropp et 
488 al., 2012; Proefrock \& Hoke, 1995) on tinnitus population, which could have given additional 489 information on habituation in tinnitus. However, the current review tried to integrate the findings 490 of each study to give a better insight into attention and habituation in tinnitus.

491

492

493

494

495

496

497

498

499

500

501

502

503

504

505

506

507

508

509

510

511

\section{Conclusion}

513 Attention is affected in individuals with tinnitus but the nature of any deficits and interaction are

514

515

516

517

518

519

520

521

522

523

524

525

526

527

528

\section{Future directions}

It is recommended that future research employs longer tasks that require concentration instead of short intensive cognitive tasks. Ecologically valid assessment of attention in simulated real-world settings or use of ecological momentary assessment (EMA) in the real world, should be added to methods employed. EMAs offer ecologically valid measurements at the expense of control over the environment. Interaction overtime between attention, habituation and different environments may be a useful avenue for research (Deutsch \& Piccirillo, 2020; Searchfield, 2014). Functional brain imaging to establish a link between inhibitory control and prefrontal cortical areas, exploring the interactions between top-down and bottom-up neurodynamic processing would all be useful additions to the field (Araneda et al., 2015; Hong et al., 2016).

The neural underpinnings of tinnitus are still debated. Until the neurophysiology of tinnitus and its physiological effects are understood, treatment should only address known contributors to tinnitus such as emotion and poor coping skills (Jackson et al., 2014). This review suggests that attention is another contributor to tinnitus that warrants clinical research. Cognitive rehabilitation programs to help shift attention to a salient stimulus, a focus on executive control of attention and auditory training therapies may be effective in this regard (Mannarelli et al., 2017; Trevis et al., 2016). difficult to interpret due to the heterogeneity in methods and populations tested. With respect to habituation, there are very few studies to draw any conclusions. There is a need to carry out studies that assess more than a single type of attention and habituation in the same participant so that the actual relationship between the two domains could be studied.

\section{Acknowledgements}

NIL

\section{References}

Andersson, G., Eriksson, J., Lundh, L.-G., \& Lyttkens, L. (2000). Tinnitus and cognitive interference: a stroop paradigm study. Journal of Speech, Language, and Hearing Research, 43(5), 1168-1173.

Andersson, G., \& McKenna, L. (1998). Tinnitus masking and depression. Audiology, 37(3), 174-182. 
529

530

531

532

533

534

535

536

537

538

539

540

541

542

543

544

545

546

547

548

549

550

551

552

553

554

555

556

557

558

559

560

561

562

563

564

565

566

567

568

569

570

571

572

573

574

575

576
Araneda, R., De Volder, A. G., Deggouj, N., \& Renier, L. (2015). Altered inhibitory control and increased sensitivity to cross-modal interference in tinnitus during auditory and visual tasks. PLoS One, 10(3), e0120387.

Araneda, R., Renier, L., Dricot, L., Decat, M., Ebner-Karestinos, D., Deggouj, N., \& De Volder, A. G. (2018). A key role of the prefrontal cortex in the maintenance of chronic tinnitus: An fMRI study using a Stroop task. Neurolmage: Clinical, 17, 325-334.

Asadpour, A., Alavi, A., Jahed, M., \& Mahmoudian, S. (2018). Cognitive memory comparison between tinnitus and normal cases using event-related potentials. Frontiers in integrative neuroscience, 12, 48.

Attias, J., Furman, V., Shemesh, Z., \& Bresloff, I. (1996). Impaired brain processing in noise-induced tinnitus patients as measured by auditory and visual event-related potentials. Ear and hearing, 17(4), 327333.

Attias, J., Urbach, D., Gold, S., \& Shemesh, Z. (1993). Auditory event related potentials in chronic tinnitus patients with noise induced hearing loss. Hearing Research, 71(1-2), 106-113.

Baigi, A., Oden, A., Almlid-Larsen, V., Barrenäs, M.-L., \& Holgers, K.-M. (2011). Tinnitus in the general population with a focus on noise and stress: a public health study. Ear and hearing, 32(6), 787789.

Barnea, G., Attias, J., Gold, S., \& Shahar, A. (1990). Tinnitus with normal hearing sensitivity: extended highfrequency audiometry and auditory-nerve brain-stem-evoked responses. Audiology, 29(1), 36-45.

Beck, A. T., \& Steer, R. (1988). Beck anxiety inventory (BAI). Überblick über Reliabilitäts-und Validitätsbefunde von klinischen und außerklinischen Selbst-und Fremdbeurteilungsverfahren, 7.

Beck, A. T., Ward, C., Mendelson, M., Mock, J., \& Erbaugh, J. (1961). Beck depression inventory (BDI). Arch Gen Psychiatry, 4(6), 561-571.

Bouton, M. E. (2007). Learning and behavior: A contemporary synthesis: Sinauer Associates.

Broadbent, D. E., Cooper, P. F., FitzGerald, P., \& Parkes, K. R. (1982). The cognitive failures questionnaire (CFQ) and its correlates. British Journal of Clinical Psychology, 21(1), 1-16.

Brodman, K., Erdmann, A. J., Lorge, I., Wolff, H. G., \& Broadbent, T. H. (1951). The Cornell medical indexhealth questionnaire: II. As a diagnostic instrument. Journal of the American Medical Association, 145(3), 152-157.

Campbell, J., Bean, C., \& LaBrec, A. (2018). Normal hearing young adults with mild tinnitus: Reduced inhibition as measured through sensory gating. Audiology Research, 8(2), 27-33.

Campbell, J., LaBrec, A., Bean, C., Nielsen, M., \& So, W. (2019). Auditory gating and extended highfrequency thresholds in normal-hearing adults with minimal tinnitus. American journal of audiology, 28(1S), 209-224.

Cardon, E., Joossen, I., Vermeersch, H., Jacquemin, L., Mertens, G., Vanderveken, O. M., ... Gilles, A. (2020). Systematic review and meta-analysis of late auditory evoked potentials as a candidate biomarker in the assessment of tinnitus. PLoS One, 15(12), e0243785.

Clarke, N. A., Henshaw, H., Akeroyd, M. A., Adams, B., \& Hoare, D. J. (2020). Associations Between Subjective Tinnitus and Cognitive Performance: Systematic Review and Meta-Analyses. Trends in hearing, 24, 2331216520918416.

Coles, R., \& Hallam, R. (1987). Tinnitus and its management. British medical bulletin, 43(4), 983-998.

Cuny, C., Norena, A., El Massioui, F., \& Chéry-Croze, S. (2004). Reduced attention shift in response to auditory changes in subjects with tinnitus. Audiology and Neurotology, 9(5), 294-302.

Davies, S., McKenna, L., \& Hallam, R. (1995). Relaxation and cognitive therapy: a controlled trial in chronic tinnitus. Psychology and Health, 10(2), 129-143.

De Ridder, D., Schlee, W., Vanneste, S., Londero, A., Weisz, N., Kleinjung, T., . . A Andersson, G. (2021). Tinnitus and tinnitus disorder: Theoretical and operational definitions (an international multidisciplinary proposal): Elsevier.

Peer] reviewing PDF | (2021:03:59620:2:0:NEW 14 Sep 2021) 
577

578

579

580

581

582

583

584

585

586

587

588

589

590

591

592

593

594

595

596

597

598

599

600

601

602

603

604

605

606

607

608

609

610

611

612

613

614

615

616

617

618

619

620

621

622

623

624

Deutsch, B., \& Piccirillo, J. (2020). Momentary Analysis of Tinnitus: Considering the Patient. Current topics in behavioral neurosciences.

Dornhoffer, J., Danner, C., Mennemeier, M., Blake, D., \& Garcia-Rill, E. (2006). Arousal and attention deficits in patients with tinnitus. International Tinnitus Journal, 12(1), 9.

dos Santos Filha, V. A. V., \& Matas, C. G. (2010). Late Auditory evoked potentials in individuals with tinnitus. Brazilian journal of otorhinolaryngology, 76(2), 263-270.

Durai, M., O'Keeffe, M. G., \& Searchfield, G. D. (2018). A review of auditory prediction and its potential role in tinnitus perception. Journal of the American Academy of Audiology, 29(06), 533-547.

Elmorsy, S. M., \& Abdeltawwab, M. M. (2013). Auditory P300: selective attention to $2 \mathrm{KHZ}$ tone-bursts in patients with idiopathic subjective tinnitus. International Journal, 1(1), 7.

Folstein, M. F., Folstein, S. E., \& McHugh, P. R. (1975). "Mini-mental state": a practical method for grading the cognitive state of patients for the clinician. Journal of psychiatric research, 12(3), 189-198.

Gabr, T. A., Abd El-Hay, M., \& Badawy, A. (2011). Electrophysiological and psychological studies in tinnitus. Auris Nasus Larynx, 38(6), 678-683.

Galazyuk, A. V., Wenstrup, J. J., \& Hamid, M. A. (2012). Tinnitus and underlying brain mechanisms. Current opinion in otolaryngology \& head and neck surgery, 20(5).

Gopinath, B., McMahon, C. M., Rochtchina, E., Karpa, M. J., \& Mitchell, P. (2010). Risk factors and impacts of incident tinnitus in older adults. Annals of epidemiology, 20(2), 129-135.

Halford, J. B., \& Anderson, S. D. (1991). Tinnitus severity measured by a subjective scale, audiometry and clinical judgement. The Journal of Laryngology \& Otology, 105(2), 89-93.

Hallam, R., Jakes, S., \& Hinchcliffe, R. (1988). Cognitive variables in tinnitus annoyance. British Journal of Clinical Psychology, 27(3), 213-222.

Hallam, R., McKenna, L., \& Shurlock, L. (2004). Tinnitus impairs cognitive efficiency. International journal of audiology, 43(4), 218-226.

Hallam, R., Rachman, S., \& Hinchcliffe, R. (1984). Psychological aspects of tinnitus. Contributions to medical psychology, 3, 31-53.

Hasson, D., Theorell, T., Wallén, M. B., Leineweber, C., \& Canlon, B. (2011). Stress and prevalence of hearing problems in the Swedish working population. BMC public health, 11(1), 1-12.

Hasson, D., Theorell, T., Westerlund, H., \& Canlon, B. (2010). Prevalence and characteristics of hearing problems in a working and non-working Swedish population. Journal of Epidemiology \& Community Health, 64(5), 453-460.

Heeren, A., Maurage, P., Perrot, H., De Volder, A., Renier, L., Araneda, R., . . Philippot, P. (2014). Tinnitus specifically alters the top-down executive control sub-component of attention: evidence from the attention network task. Behavioural brain research, 269, 147-154.

Hoke, E. S., MühInickel, W., Ross, B., \& Hoke, M. (1998). Tinnitus and event-related activity of the auditory cortex. Audiology and Neurotology, 3(5), 300-331.

Hong, S. K., Park, S., Ahn, M.-H., \& Min, B.-K. (2016). Top-down and bottom-up neurodynamic evidence in patients with tinnitus. Hearing Research, 342, 86-100.

Houdayer, E., Teggi, R., Velikova, S., Gonzalez-Rosa, J., Bussi, M., Comi, G., \& Leocani, L. (2015). Involvement of cortico-subcortical circuits in normoacousic chronic tinnitus: A source localization EEG study. Clinical Neurophysiology, 126(12), 2356-2365.

Jackson, J. G., Coyne, I. J., \& Clough, P. J. (2014). A preliminary investigation of potential cognitive performance decrements in non-help-seeking tinnitus sufferers. International journal of audiology, 53(2), 88-93.

Jastreboff, P. J. (1990). Phantom auditory perception (tinnitus): mechanisms of generation and perception. Neuroscience research, 8(4), 221-254.

Jastreboff, P. J., Gray, W. C., \& Gold, S. L. (1996). Neurophysiological approach to tinnitus patients. American Journal of Otology, 17(2), 236-240.

Peer] reviewing PDF | (2021:03:59620:2:0:NEW 14 Sep 2021) 
625

626

627

628

629

630

631

632

633

634

635

636

637

638

639

640

641

642

643

644

645

646

647

648

649

650

651

652

653

654

655

656

657

658

659

660

661

662

663

664

665

666

667

668

669

670

671

Jastreboff, P. J., \& Jastreboff, M. M. (2000). Tinnitus retraining therapy (TRT) as a method for treatment of tinnitus and hyperacusis patients. Journal of the American Academy of Audiology, 11(3), 162177.

Katsuki, F., \& Constantinidis, C. (2014). Bottom-up and top-down attention: different processes and overlapping neural systems. The Neuroscientist, 20(5), 509-521.

Kropp, P., Hartmann, M., Barchmann, D., Meyer, W., Darabaneanu, S., Ambrosch, P., . . Gerber, W.-D. (2012). Cortical habituation deficit in tinnitus sufferers: Contingent negative variation as an indicator of duration of the disease. Applied psychophysiology and biofeedback, 37(3), 187-193.

Langguth, B., Goodey, R., Azevedo, A., Bjorne, A., Cacace, A., Crocetti, A., . . Elbert, T. (2007). Consensus for tinnitus patient assessment and treatment outcome measurement: Tinnitus Research Initiative meeting, Regensburg, July 2006. Progress in brain research, 166, 525-536.

Li, Z., Gu, R., Zeng, X., Zhong, W., Qi, M., \& Cen, J. (2016). Attentional bias in patients with decompensated tinnitus: prima facie evidence from event-related potentials. Audiology and Neurotology, 21(1), 38-44.

Lima, D. O., Araújo, A. M. G. D. d., Branco-Barreiro, F. C. A., Carneiro, C. d. S., Almeida, L. N. A., \& Rosa, M. R. D. d. (2020). Auditory attention in individuals with tinnitus. Brazilian journal of otorhinolaryngology, 86(4), 461-467.

Mahmoudian, S., Farhadi, M., Najafi-Koopaie, M., Darestani-Farahani, E., Mohebbi, M., Dengler, R., . . . Danesh, A. A. (2013). Central auditory processing during chronic tinnitus as indexed by topographical maps of the mismatch negativity obtained with the multi-feature paradigm. Brain research, 1527, 161-173.

Mannarelli, D., Pauletti, C., Mancini, P., Fioretti, A., Greco, A., De Vincentiis, M., \& Fattapposta, F. (2017). Selective attentional impairment in chronic tinnitus: Evidence from an event-related potentials study. Clinical Neurophysiology, 128(3), 411-417.

Michikawa, T., Nishiwaki, Y., Kikuchi, Y., Saito, H., Mizutari, K., Okamoto, M., \& Takebayashi, T. (2010). Prevalence and factors associated with tinnitus: a community-based study of Japanese elders. Journal of epidemiology, 1005180164-1005180164.

Milner, R., Lewandowska, M., Ganc, M., Nikadon, J., Niedziałek, I., Jędrzejczak, W. W., \& Skarżyński, H. (2020). Electrophysiological correlates of focused attention on low-and high-distressed tinnitus. PLoS One, 15(8), e0236521.

Mohamad, N., Hoare, D. J., \& Hall, D. A. (2016). The consequences of tinnitus and tinnitus severity on cognition: A review of the behavioural evidence. Hearing Research, 332, 199-209.

Mohebbi, M., Daneshi, A., Asadpour, A., Mohsen, S., Farhadi, M., \& Mahmoudian, S. (2019). The potential role of auditory prediction error in decompensated tinnitus: an auditory mismatch negativity study. Brain and behavior, 9(4), e01242.

Näätänen, R. (2001). The perception of speech sounds by the human brain as reflected by the mismatch negativity (MMN) and its magnetic equivalent (MMNm). Psychophysiology, 38(1), 1-21.

Najafi, S., \& Rouzbahani, M. (2020). Auditory evoked potential P300 characteristics in adults with and without idiopathic bilateral tinnitus. Auditory and Vestibular Research.

Newman, C. W., Jacobson, G. P., \& Spitzer, J. B. (1996). Development of the tinnitus handicap inventory. Archives of Otolaryngology-Head \& Neck Surgery, 122(2), 143-148.

Park, K. H., Lee, S. H., Koo, J.-W., Park, H. Y., Lee, K. Y., Choi, Y. S., . . Woo, S.-Y. (2014). Prevalence and associated factors of tinnitus: data from the Korean National Health and Nutrition Examination Survey 2009-2011. Journal of epidemiology, JE20140024.

Philippot, P., Nef, F., Clauw, L., de Romrée, M., \& Segal, Z. (2012). A randomized controlled trial of mindfulness-based cognitive therapy for treating tinnitus. Clinical psychology \& psychotherapy, 19(5), 411-419.

PeerJ reviewing PDF | (2021:03:59620:2:0:NEW 14 Sep 2021) 
672 Polich, J. (2007). Updating P300: an integrative theory of P3a and P3b. Clinical Neurophysiology, 118(10), 673 2128-2148.

674 Polich, J. (2012). Neuropsychology of P300.

675 Proefrock, E., \& Hoke, M. (1995). Contingent magnetic variation (CMV) studied with stimuli close to the

676

677

678

679

680

681

682

683

684

685

686

687

688

689

690

691

692

693

694

695

696

697

698

699

700

701

702

703

704

705

706

707

708

709

710

711

712

713

714 hearing threshold in normal subjects and tinnitus patients. Biomagnetism: Fundamental research and clinical applications, 234-239.

Richardson, M. L. (2018). Perceptual Consequences of Tinnitus: Effects of Sensory Deficits and Top-Down Attention. UC Irvine.

Rossiter, S., Stevens, C., \& Walker, G. (2006). Tinnitus and its effect on working memory and attention. Journal of Speech, Language, and Hearing Research.

Searchfield, G. D. (2014). Tinnitus what and where: an ecological framework. Frontiers in neurology, 5, 271.

Shargorodsky, J., Curhan, G. C., \& Farwell, W. R. (2010). Prevalence and characteristics of tinnitus among US adults. The American journal of medicine, 123(8), 711-718.

Shen, C.-L., Chou, T.-L., Lai, W.-S., Hsieh, M. H., Liu, C.-C., Liu, C.-M., \& Hwu, H.-G. (2020). P50, N100, and P200 auditory sensory gating deficits in schizophrenia patients. Frontiers in Psychiatry, 11, 868.

Shinn-Cunningham, B. G., \& Best, V. (2008). Selective attention in normal and impaired hearing. Trends in amplification, 12(4), 283-299.

Shiraishi, T., Sugimoto, K., Kubo, T., Matsunaga, T., Nageishi, Y., \& Simokochi, M. (1991). Contingent negative variation enhancement in tinnitus patients. American journal of otolaryngology, 12(5), 267-271.

Slater, R., Terry, M., \& Davis, B. (1987). Tinnitus: a guide for sufferers and professionals: Taylor \& Francis.

Snaith, R. P. (2003). The hospital anxiety and depression scale. Health and quality of life outcomes, 1(1), 1-4.

Spielberger, C. D. (1983). State-trait anxiety inventory for adults.

Stevens, C., Walker, G., Boyer, M., \& Gallagher, M. (2007). Severe tinnitus and its effect on selective and divided attention: acufeno severo y sus efectos sobre la atención selectiva y dividida. International journal of audiology, 46(5), 208-216.

Tegg-Quinn, S., Bennett, R. J., Eikelboom, R. H., \& Baguley, D. M. (2016). The impact of tinnitus upon cognition in adults: A systematic review. International journal of audiology, 55(10), 533-540.

Trevis, K. J., McLachlan, N. M., \& Wilson, S. J. (2016). Cognitive mechanisms in chronic tinnitus: psychological markers of a failure to switch attention. Frontiers in psychology, 7, 1262.

Vasudevan, H., Palaniswamy, H. P., \& Balakrishnan, R. (2019). Sensory and cognitive components of auditory processing in individuals with tinnitus. American journal of audiology, 28(4), 834-842.

Waechter, S., \& Brännström, K. J. (2015). The impact of tinnitus on cognitive performance in normalhearing individuals. International journal of audiology, 54(11), 845-851.

Wang, Y., Zhang, J. N., Hu, W., Li, J. J., Zhou, J. X., Zhang, J. P., . . Li, M. (2018). The characteristics of cognitive impairment in subjective chronic tinnitus. Brain and behavior, 8(3), e00918.

Wilson, P. H., Henry, J., Bowen, M., \& Haralambous, G. (1991). Tinnitus reaction questionnaire: psychometric properties of a measure of distress associated with tinnitus. Journal of Speech, Language, and Hearing Research, 34(1), 197-201.

Zung, W. W. (1965). A self-rating depression scale. Archives of general psychiatry, 12(1), 63-70.

Zung, W. W., Richards, C. B., \& Short, M. J. (1965). Self-rating depression scale in an outpatient clinic: further validation of the SDS. Archives of general psychiatry, 13(6), 508-515.

716

717

718

Peer] reviewing PDF | (2021:03:59620:2:0:NEW 14 Sep 2021) 


\section{Table $\mathbf{1}$ (on next page)}

Tinnitus characteristics reported in the review

Note: NR- Not Reported, VAS- Visual Analogue Scale, TQ- Tinnitus Questionnaire, TCSHQTinnitus Case Sample History Questionnaire, STSS- Subjective Tinnitus Severity Rating, TRQTinnitus Reaction Questionnaire, QIPA- Tinnitus Psychological Impact Questionnaire, TSCHQTinnitus Sample Case History Questionnaire, THI- Tinnitus Handicap Inventory, S-TQ- Short version of Tinnitus Questionnaire. 
1

2 Table 1: Tinnitus characteristics reported in the review.

3

\begin{tabular}{|c|c|c|c|c|c|c|c|}
\hline $\begin{array}{l}\text { Study } \\
\text { (no. of } \\
\text { tinnitus } \\
\text { participants) }\end{array}$ & Pitch & $\begin{array}{l}\text { Loudnes } \\
\text { s }\end{array}$ & $\begin{array}{l}\text { Lateralit } \\
\mathbf{y}\end{array}$ & $\begin{array}{l}\text { Previou } \\
\text { s } \\
\text { treatme } \\
\text { nt }\end{array}$ & $\begin{array}{l}\text { Duration of } \\
\text { tinnitus } \\
\text { (in months) }\end{array}$ & Severity & $\begin{array}{l}\text { Scale used to } \\
\text { measure }\end{array}$ \\
\hline $\begin{array}{l}\text { Andersson et } \\
\text { al. }(2000) \\
(n=23)\end{array}$ & $\begin{array}{l}\text { Mean } \\
5.59 \\
\mathrm{kHz}\end{array}$ & $\begin{array}{l}\text { 19dBSL } \\
(18)\end{array}$ & $\mathrm{B} / \mathrm{L}$ & $\begin{array}{l}\text { Yes, } \\
8 / 23 \\
\text { underwe } \\
\text { nt }\end{array}$ & $6.3(4.1)$ & Severe & S-TQ \\
\hline $\begin{array}{l}\text { Araneda et } \\
\text { al. }(2015) \\
(n=17)\end{array}$ & $\begin{array}{l}0.25-8 \\
\mathrm{kHz}\end{array}$ & NR & $\mathrm{B} / \mathrm{L}$ & No & 6 and above & $\begin{array}{l}\text { Mild to } \\
\text { Severe }\end{array}$ & TSCHQ, THI \\
\hline $\begin{array}{l}\text { Attias et al. } \\
(1993) \\
(n=12)\end{array}$ & $\begin{array}{l}5-8 \\
\mathrm{kHz}\end{array}$ & $\begin{array}{l}10- \\
20 \mathrm{dBSL}\end{array}$ & $\mathrm{B} / \mathrm{L}$ & NR & 60 and above & NR & Not used \\
\hline $\begin{array}{l}\text { Attias et al. } \\
(1996) \\
(n=21)\end{array}$ & NR & NR & $\mathrm{B} / \mathrm{L}$ & NR & 84 and above & Chronic & $\begin{array}{l}\text { Tinnitus } \\
\text { severity and } \\
\text { symptom } \\
\text { profile } \\
\text { questionnaire }\end{array}$ \\
\hline $\begin{array}{l}\text { Cuny et al. } \\
(2004) \\
(n=20)\end{array}$ & NR & NR & $\mathrm{B} / \mathrm{L}$ & NR & NR & NR & STSS \\
\hline $\begin{array}{l}\text { Heeren et al. } \\
(2014) \\
(n=20)\end{array}$ & NR & NR & $\mathrm{B} / \mathrm{L}$ & $\begin{array}{l}\text { No } \\
\text { masker } \\
\text { related } \\
\text { treatmen } \\
\mathrm{t}\end{array}$ & 6 & NR & QIPA \\
\hline $\begin{array}{l}\text { Hong et al. } \\
(2016) \\
(n=14)\end{array}$ & $8 \mathrm{kHz}$ & NR & $\mathrm{B} / \mathrm{L}$ & No & 3 and above & $\begin{array}{l}\text { Range } \\
\text { varied }\end{array}$ & TQ and THI \\
\hline $\begin{array}{l}\text { Houdayer et } \\
\text { al. }(2015) \\
(n=17)\end{array}$ & $\begin{array}{l}4,6, \& \\
8 \mathrm{kHz}\end{array}$ & $\begin{array}{l}6.41 \\
(2.96) \\
d B S L\end{array}$ & $\mathrm{U} / \mathrm{L}$ & NR & 22 & Chronic & THI \\
\hline $\begin{array}{l}\text { Jackson et } \\
\text { al. }(2014) \\
(n=33) \\
\end{array}$ & NR & NR & NR & No & Not above12 & $\begin{array}{l}\text { Low- } \\
\text { moderate }\end{array}$ & STSS \\
\hline $\begin{array}{l}\text { Mahmoudia } \\
\text { n et al. } \\
(2013)\end{array}$ & NR & NR & $\begin{array}{l}\text { Mostly in } \\
\text { the head }\end{array}$ & No & 3 and above & Chronic & THI and TQ \\
\hline
\end{tabular}




\begin{tabular}{|c|c|c|c|c|c|c|c|}
\hline$(n=28)$ & & & & & & & \\
\hline $\begin{array}{l}\text { Manarelli et } \\
\text { al. }(2016) \\
(n=20)\end{array}$ & NR & NR & $\mathrm{B} / \mathrm{L}$ & NR & 6 and above & Chronic & THI \\
\hline $\begin{array}{l}\text { Mohebbi et } \\
\text { al. }(2019) \\
(n=20)\end{array}$ & $\begin{array}{l}6-9 \\
\mathrm{kHz}\end{array}$ & $\begin{array}{l}\text { VAS } \\
8.2 \\
(1.23)\end{array}$ & $\mathrm{B} / \mathrm{L}$ & $\begin{array}{l}\text { Not in } \\
\text { the past } \\
\text { 3months }\end{array}$ & 6 and above & $\begin{array}{l}\text { Decompen } \\
\text { sated } \\
\text { tinnitus }\end{array}$ & THI and TQ \\
\hline $\begin{array}{l}\text { Rossiter et } \\
\text { al. }(2006) \\
(n=18)\end{array}$ & NR & NR & $\mathrm{B} / \mathrm{L}$ & NR & 3 and above & $\begin{array}{l}\text { Moderate } \\
\text { tinnitus }\end{array}$ & TRQ \\
\hline $\begin{array}{l}\text { Shirashi et } \\
\text { al. }(1991) \\
(n=20)\end{array}$ & NR & NR & NR & NR & NR & NR & NR \\
\hline $\begin{array}{l}\text { Stevens et al. } \\
(2007) \\
(n=11)\end{array}$ & NR & NR & $\mathrm{B} / \mathrm{L}$ & NR & 24 and above & Severe & TQ \\
\hline $\begin{array}{l}\text { Trevis et al. } \\
(2016) \\
(n=26)\end{array}$ & NR & $\begin{array}{l}\text { VAS } \\
41.92 \\
(22.18)\end{array}$ & $\mathrm{B} / \mathrm{L}$ & NR & 3 and above & Chronic & $\begin{array}{l}\text { TCSHQ \& } \\
\text { THI }\end{array}$ \\
\hline $\begin{array}{l}\text { Waechter et } \\
\text { al. }(2015) \\
(n=20)\end{array}$ & NR & NR & $\mathrm{B} / \mathrm{L}$ & Yes (8) & 6 and above & $\begin{array}{l}40.05 \\
\text { (moderate) }\end{array}$ & $\begin{array}{lr}\text { TQ } & (6 \\
\text { months } & \text { post } \\
\text { testing) } & \\
\end{array}$ \\
\hline
\end{tabular}

5 Note: B/L-Bilateral, U/L-Unilateral, NR-Not Reported, dBSL-decibel sensation Level, VAS-

6 Visual Analogue Scale, TQ-Tinnitus Questionnaire, TCSHQ-Tinnitus Case Sample History

7 Questionnaire, STSS-Subjective Tinnitus Severity Rating, TRQ-Tinnitus Reaction

8 Questionnaire, QIPA-Tinnitus Psychological Impact Questionnaire, TSCHQ- Tinnitus Sample

9 Case History Questionnaire, THI-Tinnitus Handicap Inventory, S-TQ-Short version of Tinnitus 10 Questionnaire. 


\section{Table 2 (on next page)}

Detailed description of the hearing characteristics of participants in the included studies

Note: $d B H L$ - decibel Hearing Level, SD-Standard Deviation, HL- Hearing loss, HA- Hearing aids, kHz - kiloHertz, HFHL- High-Frequency Hearing Loss, HFAHL- High-Frequency Average Hearing Level. 
1 Table 2: Detailed description of the hearing characteristics of participants in the included studies.

\begin{tabular}{|c|c|c|c|c|}
\hline Studies & $\begin{array}{l}\text { Hearing } \\
\text { Tested }\end{array}$ & PTA Results & Matching & Additional comments \\
\hline $\begin{array}{l}\text { Andersson et } \\
\text { al. }(2000)\end{array}$ & Yes & $\begin{array}{l}17 \mathrm{dBHL}(11 \mathrm{SD}) \text { at } \\
\text { better frequency to } \\
31 \mathrm{dBHL}(27 \mathrm{SD}) \text { at } \\
\text { worst frequency }\end{array}$ & No & $\begin{array}{l}20 \text { of } 23 \text { in tinnitus group }-\mathrm{HL}, 4 \\
\text { amongst using HA }\end{array}$ \\
\hline $\begin{array}{l}\text { Araneda et } \\
\text { al. (2015) }\end{array}$ & Yes & $<35 \mathrm{dBHL}$ & Yes & NIL \\
\hline $\begin{array}{l}\text { Attias et al. } \\
(1993)\end{array}$ & Yes & Sloping loss & Yes & NIL \\
\hline $\begin{array}{l}\text { Attias et al. } \\
(1996)\end{array}$ & Yes & Sloping loss & Yes & NIL \\
\hline $\begin{array}{l}\text { Cuny et al. } \\
(2004)\end{array}$ & Yes & $\begin{array}{l}<10 \mathrm{dBHL} \text { till } 2 \mathrm{kHz} \\
\text { and } 30 \mathrm{dBHL} \text { in later } \\
\text { frequencies }\end{array}$ & No & NIL \\
\hline $\begin{array}{l}\text { Heeren et al. } \\
(2014)\end{array}$ & No & - & NA & $\begin{array}{l}\text { Medical check by Physician in } \\
\text { hearing disorder and had } \\
\text { sufficient ability to follow } \\
\text { instructions }\end{array}$ \\
\hline $\begin{array}{l}\text { Hong et al. } \\
(2016)\end{array}$ & Yes & $<25 \mathrm{dBHL}$ & $\begin{array}{l}\text { NR } \\
\text { (appears } \\
\text { matched) }\end{array}$ & NIL \\
\hline $\begin{array}{l}\text { Houdayer et } \\
\text { al. (2015) }\end{array}$ & Yes & $<15 \mathrm{dBHL}$ & NR & 5 individuals had hyperacusis \\
\hline $\begin{array}{l}\text { Jackson et al. } \\
(2014)\end{array}$ & No & - & NA & $\begin{array}{l}\text { Comfortable conversing in a quiet } \\
\text { environment }\end{array}$ \\
\hline $\begin{array}{l}\text { Mahmoudian } \\
\text { et al. (2013) }\end{array}$ & Yes & $\begin{array}{l}<20 \mathrm{~dB} \text { till } 2 \mathrm{kHz} \& \\
40 \mathrm{~dB} \text { from } 4 \mathrm{kHz} \text { to } \\
8 \mathrm{kHz}\end{array}$ & Yes & NIL \\
\hline $\begin{array}{l}\text { Manarelli et } \\
\text { al. (2016) }\end{array}$ & Yes & $\begin{array}{l}<20 \mathrm{~dB} \text { till } 2 \mathrm{kHz} \& \\
30 \mathrm{dBHL} \text { in later } \\
\text { frequencies }\end{array}$ & No & 8 individuals' HFHL \\
\hline $\begin{array}{l}\text { Mohebbi et } \\
\text { al. (2019) }\end{array}$ & Yes & $\begin{array}{l}<20 \mathrm{~dB} \text { till } 2 \mathrm{kHz} \& \\
40 \mathrm{~dB} \text { till } 8 \mathrm{kHz}\end{array}$ & Yes & NIL \\
\hline $\begin{array}{l}\text { Rossiter et al. } \\
(2006)\end{array}$ & No & - & NA & $\begin{array}{l}1 \text { participant in tinnitus group } \\
\text { wore } \mathrm{HA}, 14 \text { others self-report of } \\
\text { mild to moderate HL }\end{array}$ \\
\hline Shirashi et al. & Yes & Minimum 5.5dBHL & No & Control audiogram data not \\
\hline
\end{tabular}




\begin{tabular}{|l|l|l|l|l|}
\hline (1991) & & $\begin{array}{l}\text { (9.16SD) @1 kHz to } \\
\text { maximum of } \\
22.08 \mathrm{dBHL} \\
(21.36 \mathrm{SD}) @ 8 \mathrm{kHz}\end{array}$ & & available - stated as normal \\
\hline $\begin{array}{l}\text { Stevens et al. } \\
\mathbf{( 2 0 0 7 )}\end{array}$ & Yes & $\begin{array}{l}\text { HFAHL } \\
37.24 \mathrm{dBHL}\end{array}$ & No & $\begin{array}{l}\text { TG- 8 HFHL (6 -moderate \& 2 } \\
\text { severe) } \\
\text { CG- 6 HFHL (5 mild \& } \\
\text { profound) }\end{array}$ \\
\hline $\begin{array}{l}\text { Trevis et al. } \\
\text { (2016) }\end{array}$ & Yes & $<25 \mathrm{dBHL}$ & Yes & $\begin{array}{l}\text { 3 in CT group had HL (1 slight \& } \\
\text { 2 moderate) } \\
\text { Removal made no change, hence } \\
\text { retained }\end{array}$ \\
\hline $\begin{array}{l}\text { Waechter et } \\
\text { al. (2015) }\end{array}$ & Yes & $<20 \mathrm{dBHL}$ & Yes & NIL \\
\hline
\end{tabular}

2 Note: PTA Results- Pure Tone Audiometric test results, HFAHL- high frequency average hearing 3 level (500, 1000, 2000 and 4000Hz), dBHL-decibel Hearing Level, SD-Standard Deviation, HL-

4 Hearing loss, HA-Hearing aids, kHz - kiloHertz, HFHL-High Frequency Hearing Loss, HF AHL-

5 High Frequency Average Hearing Level. 


\section{Table 3 (on next page)}

Tests and Outcome of various studies in the review

Note: A-Auditory, V-Visual, A+V - Auditory and Visual stimulus, E-Electrophysiological paradigm, B-Behavioural paradigm, MMN-Mismatch Negativity. 
Table 3: Tests and Outcome of various studies in the review.

\begin{tabular}{|c|c|c|c|c|c|}
\hline Studies & Paradigm & Test done & Stimulus & Outcome & Study results - TG \\
\hline $\begin{array}{c}\text { Andersson et al. } \\
(\mathbf{2 0 0 0 )}\end{array}$ & $\mathrm{B}$ & Stroop task & $\mathrm{V}$ & $\begin{array}{l}\text { TG longer RT in classical and tinnitus word } \\
\text { Stroop task }\end{array}$ & Executive function affected \\
\hline Araneda et al. (2015) & $\mathrm{B}$ & Go/no-go task & $\mathrm{A}+\mathrm{V}$ & $\begin{array}{l}\text { TG slower RT and more false alarms in } \\
\text { auditory modality }\end{array}$ & $\begin{array}{l}\text { Cognitive inhibitory control } \\
\text { mechanism affected }\end{array}$ \\
\hline Attias et al. (1993) & $\mathrm{E}$ & $\begin{array}{l}\text { Oddball and Variable } \\
\text { P300 }\end{array}$ & $\mathrm{A}$ & $\begin{array}{l}\text { TG P300 amplitude reduced, no changes in } \\
\text { latency }\end{array}$ & Altered cognitive processing \\
\hline Attias et al. (1996) & $\mathrm{E}$ & Oddball P300 & $\mathrm{A}+\mathrm{V}$ & $\begin{array}{c}\text { A: TG P300 prolonged and reduced amplitude } \\
\text { V: prolonged P3 TG }\end{array}$ & Selective attention affected \\
\hline Cuny et al. (2004) & B & Categorization task & A & $\begin{array}{l}\text { Severe tinnitus performed less efficient than } \\
\text { mild and moderate tinnitus }\end{array}$ & $\begin{array}{c}\text { Disturbance in the automatic attention } \\
\text { process }\end{array}$ \\
\hline Heeren et al. (2014) & B & ANT & $\mathrm{V}$ & $\begin{array}{l}\text { TG longer RT. Alerting and orienting attention } \\
\text { preserved with deficit in executive attention }\end{array}$ & $\begin{array}{c}\text { A specific deficit in Top-down control } \\
\text { and attention }\end{array}$ \\
\hline Hong et al. (2016) & $\mathrm{E}$ & Oddball P300 & $\mathrm{A}$ & TG lower P300 amplitude & Impaired top-down attentional process \\
\hline Houdayer et al. (2015) & $\mathrm{E}$ & Oddball P300 & $\mathrm{A}$ & No latency or amplitude difference in P300 & Voluntary attention not affected \\
\hline Jackson et al. (2014) & B & $\begin{array}{c}\text { Stroop task \& Vienna } \\
\text { Determination Test }\end{array}$ & $\mathrm{V}$ & TG longer RT, error rate no difference & Cognitive efficiency was affected. \\
\hline Manarelli et al. (2016) & E & Novelty P300 & $\mathrm{A}$ & $\begin{array}{c}\text { TG lower P300a amplitude, P300b } \\
\text { comparable }\end{array}$ & $\begin{array}{l}\text { A general slowing in the attentional } \\
\text { switch to a salient stimulus }\end{array}$ \\
\hline Mohebbi et al. (2019) & $\mathrm{E}$ & MMN & A & $\begin{array}{l}\text { Lower amplitude and AUC for high frequency } \\
\text { and SG deviants in decompensated tinnitus. }\end{array}$ & $\begin{array}{l}\text { A deficit in the pre-attentive change } \\
\text { detection process }\end{array}$ \\
\hline Rossiter et al. (2006) & B & $\begin{array}{c}\text { Reading span test \& } \\
\text { divided attention }\end{array}$ & $\mathrm{A}+\mathrm{V}$ & $\begin{array}{c}\text { TG lower reading span and longer RT } \\
\text { category naming task }\end{array}$ & $\begin{array}{c}\text { Controlled conscious cognitive process } \\
\text { disrupted }\end{array}$ \\
\hline Shirashi et al. (1991) & $\mathrm{E}$ & $\begin{array}{c}\text { P300 \& Contingent } \\
\text { Negative Variation (CNV) }\end{array}$ & $\mathrm{A}+\mathrm{V}$ & No latency or amplitude difference in P300 & Comparable \\
\hline Stevens et al. (2007) & B & $\begin{array}{c}\text { Stroop test \& Visual } \\
\text { divided attention }\end{array}$ & $\mathrm{V}$ & $\begin{array}{c}\text { TG longer RT in word reading and category } \\
\text { naming task }\end{array}$ & $\begin{array}{l}\text { General degenerative effect on } \\
\text { selective and divided attention }\end{array}$ \\
\hline Trevis et al. (2016) & $\mathrm{B}$ & Cognitive Control, & $\mathrm{V}$ & TG had Slow RT for cognitive control and & Reduced control to switch attention \\
\hline
\end{tabular}




\begin{tabular}{|c|c|c|c|c|c|}
\hline & & $\begin{array}{c}\text { Inhibition \& Working } \\
\text { Memory test }\end{array}$ & & inhibitory task & No difference in RT and Accuracy \\
\hline Waechter et al. (2015) & B & Modified Stroop task & V & Results comparable \\
\hline
\end{tabular}

2 Note: A-Auditory, V-Visual, A+V-Auditory and Visual stimulus, E- Electrophysiological paradigm, B-Behavioural paradigm, MMN-Mismatch

3 Negativity, TG-Tinnitus Group, AUC-Area Under the Curve, SG-Silent Gap, RT-Reaction Time 


\section{Table 4 (on next page)}

Stimulus and recording characteristics of electrophysiological studies

Note: Hz- Hertz, kHz- kiloHertz, dBSPL- decibel Sound Pressure Level, TP- Tinnitus Pitch, PTPure Tones 
1 Table 4: Stimulus and recording characteristics of electrophysiological studies.

\begin{tabular}{|c|c|c|c|c|}
\hline Studies & $\begin{array}{l}\text { Instrument - } \\
\text { Recording } \\
\end{array}$ & No. electrodes used & Ratio & Stimulus info \\
\hline $\begin{array}{l}\text { Attias et al. } \\
\text { (1996) }\end{array}$ & $\begin{array}{l}\text { ORGIL BPM } \\
30 \text { system }\end{array}$ & $\begin{array}{l}5 \text { electrodes } \\
(\mathrm{Fz}, \mathrm{Cz}, \mathrm{Pz}, \mathrm{T} 3 \text { \& T4) }\end{array}$ & $80: 20$ & $\begin{array}{l}1 \mathrm{kHz} \quad \& \quad 2 \mathrm{kHz} \\
\mathrm{PT}\end{array}$ \\
\hline $\begin{array}{l}\text { Attias et al. } \\
\text { 1993) }\end{array}$ & $\begin{array}{l}\text { ORGIL BPM } \\
30 \text { system }\end{array}$ & $\begin{array}{l}3 \text { electrodes } \\
(\mathrm{Fz}, \mathrm{Cz} \& \mathrm{Pz})\end{array}$ & $80: 20$ & $\begin{array}{l}1 \mathrm{kHz} \& 2 \mathrm{kHz} \\
\mathrm{PT} \text { at } 40 \mathrm{dBSL}\end{array}$ \\
\hline $\begin{array}{l}\text { Hong et al. } \\
(2016)\end{array}$ & $\begin{array}{l}\text { BrainAmp } \\
\text { DC amp }\end{array}$ & $\begin{array}{l}32 \text { electrodes } \\
(10-10 \text { system })\end{array}$ & $80: 20$ & $\begin{array}{l}0.5 \mathrm{kHz} \& \mathrm{TP} / \\
8 \mathrm{kHz} \text { Pure tone } \\
\text { at } 50 \mathrm{dBSPL}\end{array}$ \\
\hline $\begin{array}{l}\text { Houdayer et } \\
\text { al. (2015) }\end{array}$ & $\begin{array}{l}\text { Brainvision } \\
\text { analyse } 2.0\end{array}$ & $\begin{array}{l}29 \text { electrodes } \\
(10-20 \text { system })\end{array}$ & $80: 20$ & $\begin{array}{l}1 \mathrm{kHz} \quad \& \quad 2 \mathrm{kHz} \\
\mathrm{PT}\end{array}$ \\
\hline $\begin{array}{l}\text { Mahmoudian } \\
\text { et al. (2013) }\end{array}$ & $\begin{array}{l}\text { BRAIN } \\
\text { QUICK LTM }\end{array}$ & $\begin{array}{l}29 \text { scalp electrodes } \\
(10-10 \text { system })\end{array}$ & $\begin{array}{l}50: 50 \quad(10 \% \\
\text { each deviant })\end{array}$ & $\begin{array}{l}0.5 \mathrm{kHz}, 1 \mathrm{kHz} \& \\
1.5 \mathrm{kHz} \text { PT at } \\
65 \mathrm{dBSPL}\end{array}$ \\
\hline $\begin{array}{l}\text { Manarelli et } \\
\text { al. (2016) }\end{array}$ & $\begin{array}{l}\text { Miar Sirius } \\
\text { EEG-EP } \\
\text { Multifunction } \\
\text { system }\end{array}$ & $\begin{array}{l}\text { Multi- channel } \\
\text { (Frontal, central \& } \\
\text { parietal sites) } \\
10-20 \text { system }\end{array}$ & $80: 10: 10$ & $\begin{array}{lr}0.5 \mathrm{kHz}, & 1 \mathrm{kHz} \\
\mathrm{PT} \text { and } & \text { novel } \\
\text { sound } & \text { at } \\
\text { 80dBSPL } & \\
\end{array}$ \\
\hline $\begin{array}{l}\text { Mohebbi et } \\
\text { al. (2019) }\end{array}$ & $\begin{array}{l}\text { BRAIN } \\
\text { QUICK LTM }\end{array}$ & $\begin{array}{l}29 \text { scalp electrodes } \\
(10-10 \text { system) }\end{array}$ & $\begin{array}{l}50: 50 \quad(12.5 \% \\
\text { each deviant })\end{array}$ & $\begin{array}{l}7.5 \mathrm{kHz}, 8 \mathrm{kHz} \& \\
8.5 \mathrm{kHz} \quad \mathrm{PT} \text {, } \\
85 \mathrm{dBSPL}\end{array}$ \\
\hline $\begin{array}{l}\text { Shirashi et al. } \\
\text { (1991) }\end{array}$ & NR & $\begin{array}{l}3 \text { electrodes } \\
\text { central \& parietal, } \\
\text { sites }\end{array}$ & $\begin{array}{l}\mathrm{S} 1-\mathrm{S} 2 \\
(50: 50)\end{array}$ & $\begin{array}{l}\text { Tone burst at } \\
1 \mathrm{kHz} \text { at } \\
85 \mathrm{dBHL} \& \text { light } \\
\text { flash }\end{array}$ \\
\hline
\end{tabular}

2 Note: Hz-Hertz, kHz-kiloHertz, dBSPL-decibel Sound Pressure Level, TP-Tinnitus Pitch, PT-

3 Pure Tones 
Figure 1

\section{PRISMA Flowchart}
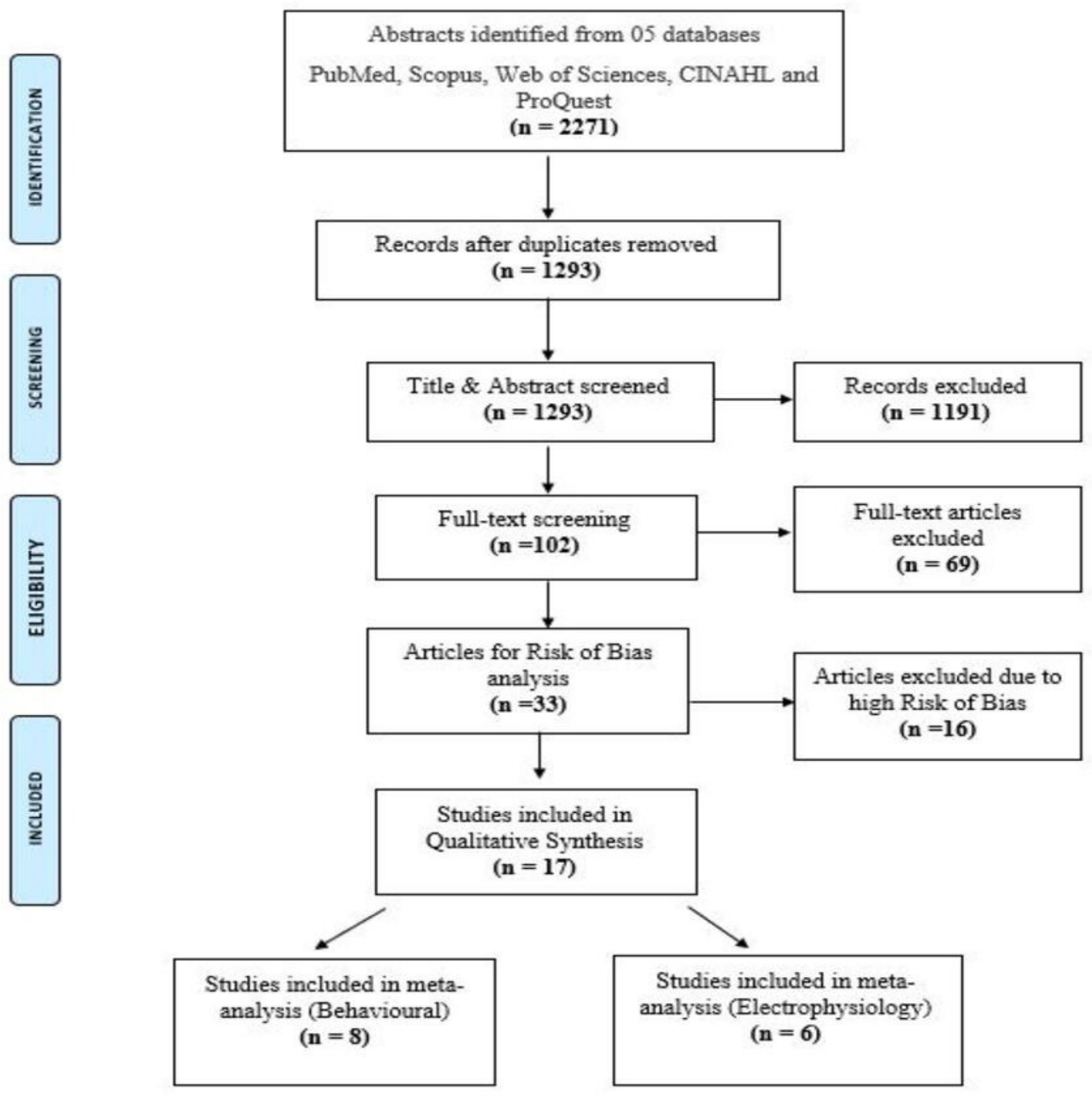
Figure 2

Meta-analysis on behavioural test of attention

The figure indicates all the behavioral measures of attention in individuals with and without tinnitus. A random effects meta-analysis was performed using the standardized mean difference (SMD) of the reaction time obtained from various studies. 


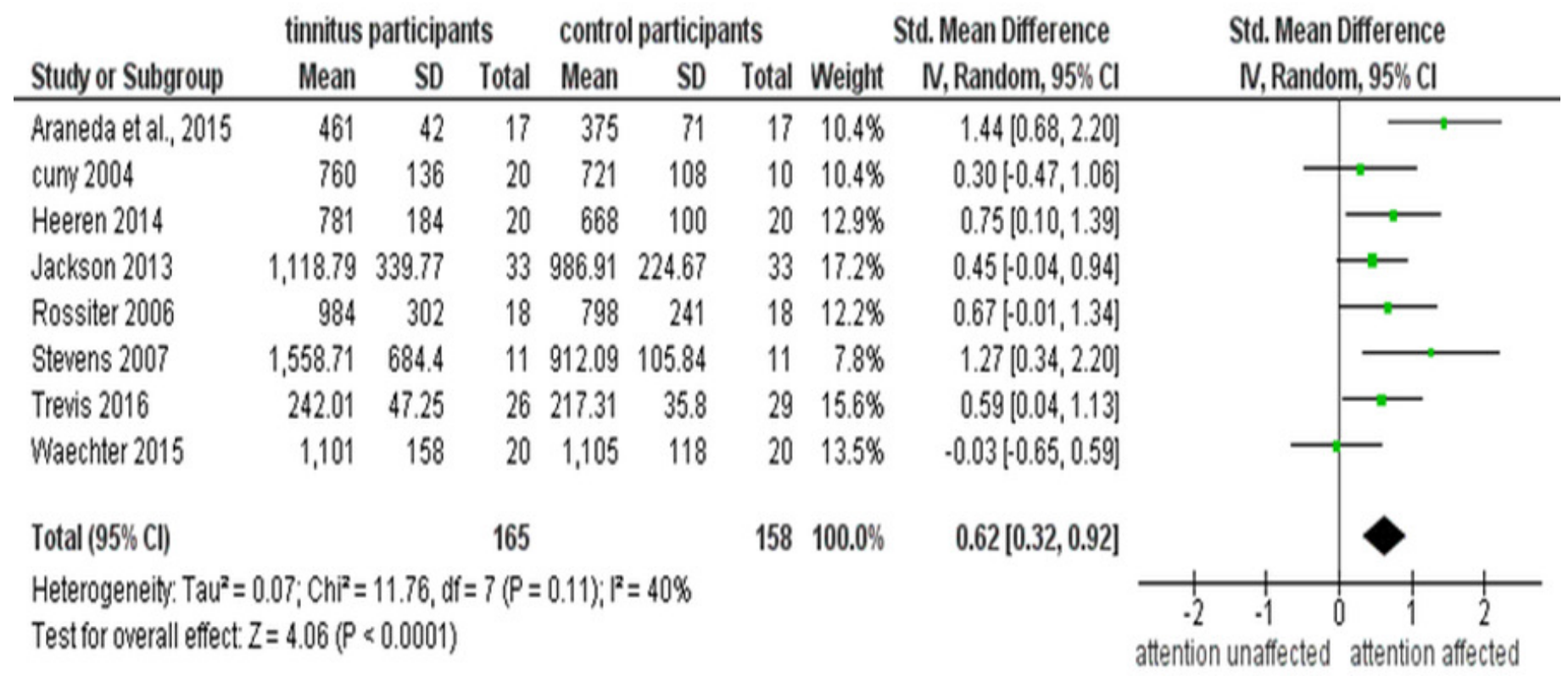




\section{Figure 3}

Figure3_subgroup analysis of attention in tinnitus with hearing matched studies

A random effects meta-analysis of three studies that have matched for hearing between the tinnitus and control group. Standardized Mean Difference (SMD) of both the groups were used to check for the overall effect size. 


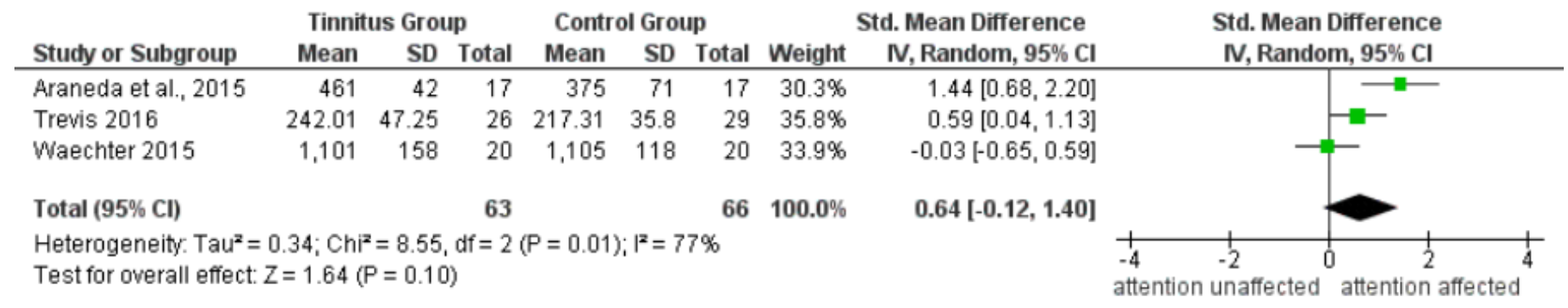




\section{Figure 4}

Figure 4_subgroup analysis of attention in tinnitus with hearing unmatched studies

A random effects meta-analysis of five studies those have not matched for hearing between the tinnitus and control group. Standardized Mean Difference (SMD) of both the groups were used to check for the overall effect size. 


\begin{tabular}{lrrrrrrr} 
& \multicolumn{3}{c}{ Tinnitus Group } & \multicolumn{2}{c}{ Control Group } & \multicolumn{1}{c}{ Std } \\
Study or Subgroup & Mean & SD & Total & Mean & SD & Total & Weight \\
\hline cuny 2004 & 760 & 136 & 20 & 721 & 108 & 10 & $14.7 \%$ \\
Heeren 2014 & 781 & 184 & 20 & 668 & 100 & 20 & $20.7 \%$ \\
Jackson 2013 & $1,118.79$ & 339.77 & 33 & 986.91 & 224.67 & 33 & $35.8 \%$ \\
Rossiter 2006 & 984 & 302 & 18 & 798 & 241 & 18 & $18.9 \%$ \\
Stevens 2007 & $1,558.71$ & 684.4 & 11 & 912.09 & 105.84 & 11 & $9.9 \%$ \\
& & & & & & & \\
Total (95\% Cl) & & & $\mathbf{1 0 2}$ & & & $\mathbf{1 0 0 . 0} \%$
\end{tabular}

otal $(95 \% \mathrm{Cl})$

102

Std. Mean Difference

Std. Mean Difference IV, Random, $95 \% \mathrm{Cl}$ IV, Random, $95 \% \mathrm{Cl}$

Heterogeneity. $\operatorname{Tau}^{2}=0.00 ; \mathrm{Chi}^{2}=3.17, \mathrm{df}=4(\mathrm{P}=0.53) ; \mathrm{I}^{2}=0 \%$

Test for overall effect: $Z=4.10(P<0.0001)$

$0.30[-0.47,1.06]$
$0.75[0.10,1.39]$
$0.45[-0.04,0.94]$
$0.67[-0.01,1.34]$
$1.27[0.34,2.20]$
$\mathbf{0 . 6 1}[0.32,0.90]$

$0.61[0.32,0.90]$

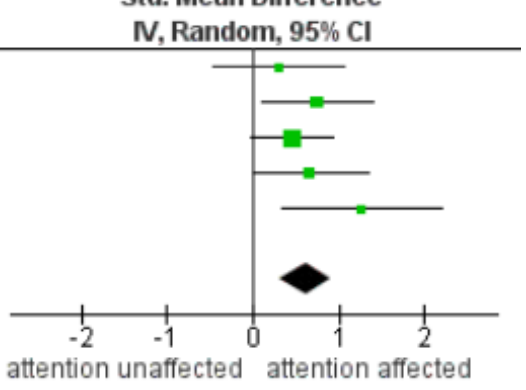




\section{Figure 5}

Figure5_Meta-analysis of P300 amplitude

A random effects meta-analysis of P300 amplitude between the control and tinnitus group. The mean difference (MD) between the P300 amplitude was used to check for the overall effect size. 


\section{control group tinnitus group Mean Difference Mean Difference}

\begin{tabular}{|c|c|c|c|c|c|c|c|c|c|c|}
\hline Study or Subgroup & Mean & SD & Total & Mean & SD & Total & Weight & N, Random, $95 \% \mathrm{Cl}$ & N, Randon & $\mathrm{m}, 95 \% \mathrm{Cl}$ \\
\hline Attias 1993 & 4.8 & 1.47 & 12 & 2.1 & 1.47 & 12 & $18.9 \%$ & $2.70[1.52,3.88]$ & & $\rightarrow$ \\
\hline Attias 1996 & 2.7 & 1.5 & 21 & 1.2 & 0.8 & 21 & $23.1 \%$ & $1.50[0.77,2.23]$ & & 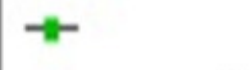 \\
\hline Hong 2016 & 14.73 & 7.6 & 14 & 6.92 & 7.6 & 14 & $2.5 \%$ & $7.81[2.18,13.44]$ & & \\
\hline Houdayer 2015 & 15.4 & 1.4 & 17 & 15.9 & 0.9 & 17 & $22.6 \%$ & $.0 .50[-1.29,0.29]$ & -1 & \\
\hline Manarelli 2016 & 6.2 & 0.4 & 20 & 5.3 & 0.4 & 20 & $26.3 \%$ & $0.90[0.65,1.15]$ & & $\bullet$ \\
\hline Shirashi 1991 & 8.1 & 6.1 & 20 & 6.3 & 4.15 & 20 & $6.5 \%$ & $1.80[-1,43,5.03]$ & & \\
\hline Total (95\% CI) & & & 104 & & & & $100.0 \%$ & $1.30[0.35,2.24]$ & & \\
\hline \multicolumn{9}{|c|}{$\begin{array}{l}\text { Heterogeneily. Tau } u^{2}=0.86 ; \mathrm{Ch}^{2}=29.68, \mathrm{df}=5(P<0.0001) ; \mathrm{P}^{2}=83 \% \\
\text { Test for overall effect } Z=2.70(P=0.007)\end{array}$} & $\begin{array}{ccc}-4 & -2 & 0 \\
\text { Larger } P 3 \text { in TO }\end{array}$ & $\begin{array}{cc}2 & 4 \\
\text { smaller } & \text { P } 3 \text { ir }\end{array}$ \\
\hline
\end{tabular}

